\title{
The Audience Strategy and Marketing of Modern Commercial Movies: Taking "Tiny Times” as Example
}

\author{
Li Jing, Chen Chih-Chung \\ School of Journalism and Communication, Jinan University, Guangzhou 510632, China \\ Chenzz03@gmail.com
}

\begin{abstract}
Tiny times" is a commercial movie released in Chinese mainland in 2013. Although the film has some shortcomings, it got a huge success at the box office. The biggest reason for the success of the movie is audience strategy. From the packaging to the content to the plot, the film are struggling to meet the tastes of the generation of 90 s audience. a bold display of all kinds of brand clothing, famous cars, high-end restaurants and other elements. it meets fantasy of the generation of 90 s, so the fans projected their dreams onto the movie.
\end{abstract}

Index Terms - Audience Strategy, fans movie, Consumerism

\section{Introduction and Literature Review}

\section{A. Positioning of the audience}

Comparing with television and newspaper, there're few researches about the audience positioning about movie. Such as Hollywood film producers use various audience strategies to achieve the business purpose, to leverage the acceptance and loyalty of audience. But positioning is a deliberate work, and function positioning is the key for audience positioning. [1] In Mainland China, most media product focused on attracting middle class audience since 1990s, and it reflects the media and the middle class have established a direct interest and emotional identity. [2]

\section{B. Literature Review about "TinyTimes"}

"Tiny Times" is a famous and controversial movie in China 2013, with most researches around it focused on its marketing strategy. Most scholars believe that the success of this movie depended on its marketing strategy rather than its artistic performance.

Through the analysis of a variety of marketing methods film "Tiny times", from marketing and public relations dissemination to explore the marketing situation of domestic film, discussed in the context of the information age Chinese film multi screen marketing strategy. [3] The marketing model of" Tiny times "is to use the new media as incision, combined with $\mathrm{O} 2 \mathrm{O}$ (online to offline) mode, supplemented by physical activity in the form of traditional marketing, precision to reach the target audience. [4]

\section{Literature Review about "Tiny Times" and Consumerism}

The reason of tiny times success in the market is that the director of Guo Jingming took the literary creation as a complete production process, and the production process is a consumer oriented. Wang Hu explored the critical success of the film market in the view of the intertextuality, characters, consumerism, film production and consumption, and finally glimpse cultural consumption symptom of the society. [5]

\section{The significance of this topic}

Audience targeting is very important to a movie, not only increase the film's box office, but also affects the production of the movie content. Therefore, study on the positioning and audience strategy of "Tiny Times" is critical since it has a positive effect on the wider and deeper analysis and improvement of commercial film production.

\section{Content Analysis}

"Tiny times", directed by the Guo JingMing, gain 73 million yuan at the box office at the first day release, breaking the 2D movie first day box office record, In June 27, 2013. In a hot debate ,this costs of production only 30 million yuan but gains nearly 500 million yuan at the box office. Two months later, the second film "tiny times: Aoki era ", with 53.73 million yuan become days box office champion. Two movies won a total of nearly 800 million yuan at the box office. Compared with the high box-office, The reputationOf tiny times" in the movie website is extremely low, The score appeared polarization: someone gave full mark while others gave zero, it depends on the age of audience. the "tiny times" announced to the world: a new audience is on the rise.

\section{A. The first movie made for the generation after $90 \mathrm{~s}$}

Targeted audience: The mean of targeted audience is to determine the film's target audience, which based on the analysis of the market and the market for film products placeholder. As we all know, with the development of economic and the improvement of science and technology, mass communication has a change from the "public" to "small minority" or from "Focus" ,"broadcast" to "narrowcasting " . In this case, the film must make a choice to determine the most suitable one as their target audience. Who is the "tiny times" fans? what the characteristics they have?

DATATOPIA used new media data analysis method, analysed the movie's group. The data shows that the average age of the movie's audience is 20.3 years. On the other hand, more than 80 percent are women in the 90000 original microblog authors, nearly half or more are micro-blog Master. Young female audience participated actively in the " tiny times " viewing, comments, sharing, communication and debate, the number of micro-blog is several times than other films, created the secondary transmission for "tiny times". 
"Tiny times" producer, and publisher An Xiaofen said in the publicly:" tiny times " is a movie supported by fans, which targeted in 15-25 years of age, mainly is post-90s generation. This is the first movie which positioned it clear to this age. In fact, including film director, actor, or the movie content, marketing way, all of them move round this age group to set. Specifically, the reason to chose Guo Jingming as director, because he has nearly 20 million micro-blog fans, thirty million books fans, the most importance is the fans are mostly the generation of $90 \mathrm{~s}$, he is one of the biggest marketing media.

By grasping the characteristics of these fans, making movies according with this group of fans, thus let the audience change into a movie fan smoothly. This study focuses on how the movie precisely localized, which successfully won the support of fans.

\section{B. Film Package and Marketing: According to the aesthetic standards of the generation after 90s.}

The generation after 90s has become the mainstream consumer in popular television culture, they has a set of standard to the TV series, the film's aesthetic. Beautiful actress and handsome actor, which is the primary pursuit for the young audience. And they can give the first visual impact on the audience. The audience not only value the actor's appearance, but also serious about modeling. On the other hand, the "tiny-times" try to meet the requirements of the generation after $90 \mathrm{~s}$ in all aspects.

They invite young beautiful actors, all of them are popular movie idol, and try to create the perfect image for actor. For example, the actor Feng Xiaoyue, appears as a boss wearing sunglasses and Chen Xuedong, show a variety of lovely handsome action in front of the lens. And every actor topless, showing abdominal muscles. Female audience in the cinema constantly screaming: "handsome!", The generation after 90 s do not hide their love to hotties.

Besides the actor's handsome appearance, clothing also cost a lot. Actors wear variety of designer clothes in the movie, like a fashion show. The director think highly of the scene, shooting, strive to create the most beautiful picture. The director knows how to satisfy the audience, using a lot of slow shot, close-up, famous brand, heavy makeup to cater to the audience's visual requirements. Finally, script, shooting shortcomings can be ignored.

\section{Selling point: Shows the characteristics of youth with consumerism}

What kind of movies that fans most want to see? Tiny Times is on the performance of the youth, friendship, love, fashion. The story takes place in the movie, that is, the moment the fans are going through. With the development of the times, the generation after 90 s is becoming the subject of young people, their values have new features. From the existing research, most scholars believe that " the generation after 90s" values showed a tendency of diversification, realistic and utilitarian. After study, Wang Chenshen found that students' value orientation for this: in the material and spiritual, most of them inclined to choose the material; Tradition and fashion, more inclined to choose fashion; The real and the ideal, more inclined to choose the reality [6]; In other words, value orientation of the generation after 90 s has diversified and utilitarian features.

The film is filled with various substances, fashion elements, in order to cater to the generation after $90 \mathrm{~s}$ preference, For example, designer clothes, all kinds of highgrade restaurant, famous carand so on, as well as the movie characters in daily life and emotional experience, but also closely related with material. First, the movie is very exaggerated to show the brand. There are more than 70 fashion brands including clothing, accessories, handbags and so on. "the actor have to change a shape almost in every scene. "The artistic director Huang Wei, said in an interview. All the actors are wearing designer dresses, and even school uniforms are specially customized by a international brand call Burberry. In the end of the film, brand LOGO covered the entire screen, which was a real eye-opener. However, Viewers enjoy these. Fans observe each set of clothes that protagonists wear, accessories, mobile phone, research its brand and price and say in the Baidu Post Bar, "I wanted this!" There is a post with a $\mathrm{Gu} \mathrm{Li} \mathrm{(actress)} \mathrm{wearing} \mathrm{uniforms} \mathrm{in} \mathrm{Baidu} \mathrm{Post} \mathrm{Bar,} \mathrm{which}$ strongly stimulated them ,because a considerable part of the students are in school or just entered the University. They directly express dissatisfaction with their uniforms: "Our uniforms are ugly, the school is stingy." The film express the brand excitement from the ordinary audience identity, show more social gap between the rich and the poor under the complex situation, which makes the population living in the second and third tier cities to produce more resonance. The characters in the film name GuLi, she quarrel with her boyfriend, said:

"Do not be naive okay ...... love is just a sand without substance, the wind has not blown, walk a few steps will disperse...... The reason why you say 'money is not important,' and 'if I have no money, will you love me' those high-sounding words, it is because you have never experienced the day without money. You get four hundred thousand overdraft credit, without scruple swipe at posmachine above, just for a nice watch, a nice dress......"

The word embodies a conflicts in the generation after 90 s, some people are born with a golden key, while others only watch a distance. In fact, these words declaim voice of some "the generation after 90s": the material is the basis of all things, emotional is unrealistic, nothingness, difficult to accept without material; Money is indispensable to a happy life and premise.

"Tiny times" reflects the contemporary social life. The market-based economy rise in the 1990s, the growth in this environment is known in economics as the clear property rights, rational people. [7] The consumerism, the utilitarian enlarge, the movie portrait of life for young people for the first time after 90 fully onto the big screen, despite the conflict with traditional values, but also shows the reality experience of youth 90s. 
But "Tinytimes", it is the first movie which set foot in the generation after $90 \mathrm{~s}$, they face more temptations, have more desire, they make mistakes and lost themselves, but also can find their life direction, the film shows the growth process.

\section{Meet the fantasy of youth of the generation after $90 \mathrm{~s}$}

By the analysis of "tiny times" fan language, the author found that the success of the film, largely due to meet a group of fantasy fans, fans make their own dreams which unable to realize, projected onto the movie. Projection is a tendency that fans put his sort of dream, desire and disappointment to the film. That is to say, when a person can not be fully realized his ideal in the real life, they will be obsessed with an idol in the aspects of the characteristics, such as ability, appearance, family background, and success (social status and wealth), so as to satisfy the desire. [7] Therefore, the fascination of the fans, reflects their desire in reality.

The four girls in the film, live a surreal campus life, their dormitory is a big apartment, their boyfriends are similar with Bijounen in anime, rich and handsome. The actress Lin Xiao, her friends help her in different ways.--wealthy and wise like $\mathrm{Gu} \mathrm{Li}$, can easily solve any problems; As stunned as Tangwanru, good at making endless jokes; Understanding friends like nanxiang, they share everything with each other. The film, full of dramatic conflicts, As Tencent comments: as a girl, would you mind fall into the swimming pool with a handsome boy together when meeting for the first time? As a boy, would you mind letting a beautiful girl to help you clean the house? How many people will refuse to have a castle in the air glass house in the central of Shanghai?

And the Fans YvonnLee, a 21-year-old junior student, speak in the Baidu Post Bar:

The youth in movie is beautiful, full of temptations, many people in adolescence had imagined such a scene, but in fact, it may not exist in reality.

From this sentence, we know that the fans of "tiny times", They long for such a youth like movie, although it can not reach it. Fans obsessed with the movie, not for the memory of the dead youth, but they need an outlet to vent reality, and in order to make up their imperfect youth.

\section{Conclusion}

The movie "tiny times" is create for the generation after 90s. This precise positioning movie gains a huge success on the movie box office. In the film packaging, directors are carefully selected for actors, props and costumes, to meet the aesthetic standards of the generation after 90s. Based on the value orientation of them, film make the brand as a selling point, a bold display of all kinds of brand clothing, famous cars, high-end restaurants and other elements. Why the Movie catch the fans is that it meets fantasy of the generation of 90 s, so the fans projected their dreams onto a movie.

The success of "tiny times" also brought great controversy, such as money worship values, excessive use of long lenses to shoot, but the fans do not care about them. Those convinced to found their youth in the movie, in fact, is seen the youth fantasy. There is a distance between fantasy and reality, it is impossible to achieve, but when they become a real picture, fanatical fans will be desperate to indulge them.

Recognition for films, equal to their own youth fantasy affirmation, And the opposite applies as well. Others such as drama, film technology, the level of the actors, all of them can be ignored.

\section{References}

[1] Li X. \& Gu X. The Audience Positioning and Function Positioning of Media. Academic Exchange, 2003(5): 164-166. (in Chinese)

[2] Zheng J. Media, Modernity and Middle Class: the Narrative about Middle Class in Mass Media. Research of Chinese Literature, 2010(1): 88-90. (in Chinese)

[3] Zhang Y. Tiny Times: Multi-Screen Marketing in the Fans Age. Broadcasting, 2013(10): 48-49.

[4] Xiao M. Film Marketing Strategy in the Age of New Media: Case Study of "Tiny Times". Chinese Film Market, 2013(10): 23-25. (in Chinese)

[5] Wang H. Consumerism and Intertextuality: the Cultural Analysis on "Tiny Times". New Century Theatre, 2013(5): 48-53. (in Chinese)

[6] Wang C., Qian, X. \& Zhang T. Investigation and Thought about the Value Education of "90s Generation. Scientific Education, 2010(8). (in Chinese)

[7] Fu C. The viewing guide of Tiny Times: youth have regret, obscenity is innocence. Tencent, 2013-06-27.(in Chinese) 